\title{
UNTERSUCHUNGEN ÜBER DIE BESTANDTEILE UND SULFITKOCHUNG DES KIEFERNHOLZES (VII).
}

\section{KERNHOLZKOCHUNG.}

\author{
Von Tsuruo Okada. \\ (Eingegangen am 17, Sept. 1941)
}

Kiefernholz bei Calciumbisulfitkochung in kürzerer Zeit. Um den völligen Aufschluss zu erzielen, wurden noch die folgenden Untersuchungen durchgeführt.

Durch Veränderung der Zusammensetzung der Kochsäure dahin, dass der Gehalt derselben an freier und gebundener schwefliger Säure steigt, wird die Aufschlussbarkeit der Kochung gesteigert.

Zuletat wurden auch noch zur Verringerung des Unterschiedes der Diffusion der Kochsäure zwischen Kiefernkern und- splint, um die Zellengewebe zu verändern, die Späne mechanischen zwischen zwei eisernen Walzen gepresst, und ihr Verhalten für die Sulfitkochung in verschiedenen Beziehungen untersucht.

Die Versuche wurden zunächst beim Gesamt-SO $4-6 \%$ Kochsäure durchgeführt, wie folgende Angaben zeigen:

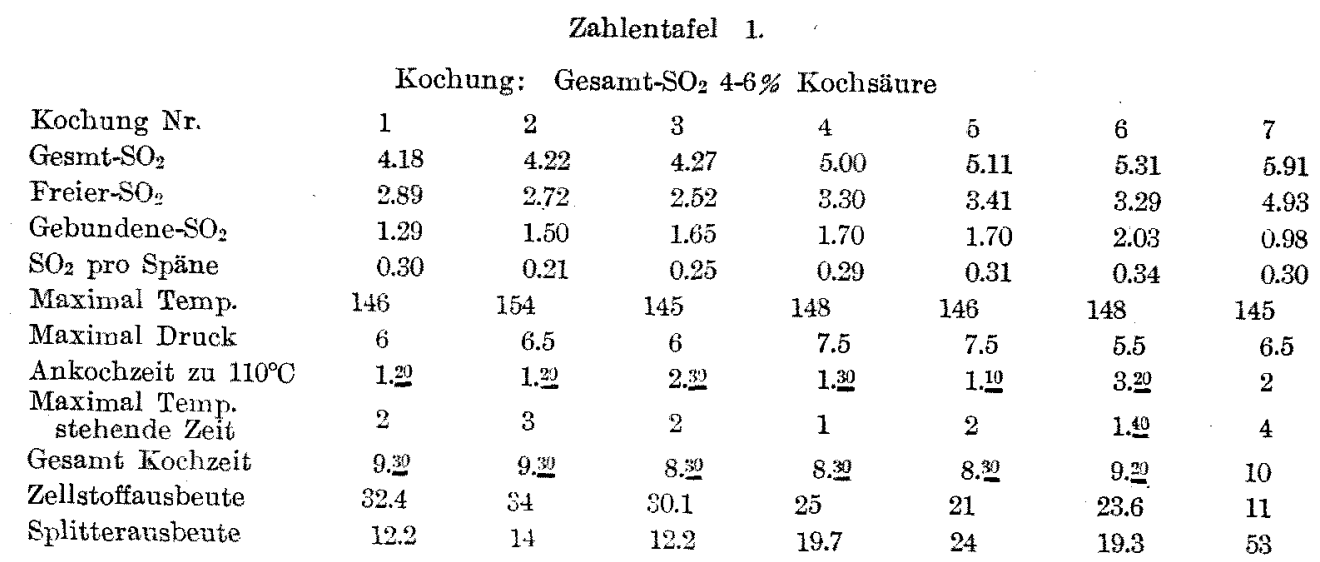

Unter diesen Bedingungen ist der völlige Aufschluss in 10 Stunden, wie aus den obigen Resultaten hervorgeht, schwierig.

$$
\text { Zahlentafel } 2 .
$$

Kochung Nr.

Gesamt-SO2

Freier- $\mathrm{SO}_{2}$

Gebundene-SO

$\mathrm{SO}_{2}$ pro Spaene

Maximal Temp.
Kochung: Gesant-SO2 Over $7 \%$

$\begin{array}{llllll}8 & 9 & 10 & 11 & 12 & 13 \\ 7.55 & 7.53 & 7.70 & 7.75 & 8.02 & 8.14 \\ 4.78 & 6.54 & 5.95 & 4.84 & 6.19 & 4.91 \\ 2.77 & 1.05 & 1.75 & 2.91 & 1.83 & 3.23 \\ 0.48 & 0.41 & 0.49 & 0.49 & 0.34 & 0.51 \\ 148 & 145 & 146 . & 150 & 147 & 145\end{array}$


Kochung Nr.

Maximal Druck

Ankochzeit zn $110^{\circ} \mathrm{C}$

Max. Temp. stehende Zeit

Gesamt Kochdauer

Zellstoffausbeute

Splitterausbeute

$\begin{array}{lll}8 & 9 & 10 \\ 6 & 7 & 6 \\ 1.30 & 1.300 & 1 \\ 2 & 3.30 & 1.201 \\ 8.200 & 7.30 & 7.20 \\ 39.2 & 21.0 & 30.4 \\ 3.5 & 43.5 & 10.9\end{array}$

11
7.5
1.20
1.40
8.40
40.9
2.4

$\begin{array}{cc}12 & 13 \\ 6.5 & 6 \\ 1.30 & 1.20 \\ 2.10 & 1.20 \\ 9 & 7.50 \\ 25.0 & 38.1 \\ 20.5 & 9.2\end{array}$

Aus der vorstehenden Zahlentafel 2 ergibt sich: wenn der Gehalt an freier und gebundener schwefliger Säure steigt, wird auch die Aufschlussfähigkeit deı Kochung gesteigert.

Da es anscheinend zur Herstellung von Zellstoffen aus Kiefernkernholz notwendig ist, mit kürzerer Kochdauer zu arbeiten, war das Ergebnis zu prüfen, wenn die Späne mechanisch gepresst und dann durch gewöhnliche Methode mit Calciumbisulfit Lösung gekocht werden. Nachfolgende Zahlen ergaben sich.

Zahlentafel 3.

Kochung: Gepresste Kernholzspäne

$\begin{array}{lcccccc}\text { Kochung Nr. } & 14 & 15 & 16 & 17 & 18 & 19 \\ \text { Gesamt-SO } & 4.15 & 5.00 & 5.04 & 5.15 & 5.25 & 7.55 \\ \text { Freier-SO } & 2.61 & 3.24 & 3.78 & 3.42 & 3.44 & 4.78 \\ \text { Gebundene-SO }_{2} & 1.54 & 1.76 & 1.26 & 1.73 & 1.81 & 2.77 \\ \text { SO }_{2} \text { pro Späne } & 0.26 & 0.27 & 0.30 & 0.40 & 0.34 & 0.48 \\ \text { Maximal Temp. } & 150 & 150 & 150 & 148 & 150 & 148 \\ \text { Maximal Druck } & 7.5 & 7.5 & 7.5 & 7.5 & 7.2 & 6 \\ \text { Ankochzeit zu } 110^{\circ} \mathrm{C} & 1.30 & 1 & 1 & 1.10 & 1.30 & 1.30 \\ \text { Max. Temp. stehende Zeit } & 3 & 2.30 & 1.40 & 2.00 & 2 & 2 \\ \text { Gesamt Kochdauer } & 10 & 7.20 & 7.30 & 9.20 & 8.30 & 8.20 \\ \text { Zellstoffausbeute } & 34 & 42.6 & 39 & 45 & 45 & 40 \\ \text { Splitterausbeute } & 1.8 & 0.9 & 1.2 & 0.4 & 5.5 & 0.4\end{array}$

Die Behandlung des Kiefernholzes durch mechanisches Pressen erleichtert das Kochen des Kernholzes mit der üblichen Calciumbisulfitlösung.

\section{ON CELLULOSE CHEMISTRY (I)}

\section{by Tsuruo Okada}

In the calcium bisulphite pulping processes, the non cellulosic constituents of wood such as lignin and pentosan are dissolved into solution, and the original amonuts of the cellulose substances are gradually decreased. The complete separation of pentosan from the cellulose is imposible. Pentosan dissolution is weekened in the last cooking period, and methylpentosan became almost constant. There a question arose as to whether these pentosan and methylpentosan are the same as the original constituents, or secondary produced from the cellulose derivatives. 